\title{
Judicialização do acesso a medicamentos em oncologia: revisão sistematizada
}

\author{
Carla MAZZUCO(1) \\ Samara Jamile MENDES ${ }^{(1)}$ \\ ${ }^{(1)}$ Faculdade de Saúde Pública, Universidade de São Paulo - USP, São Paulo, SP, Brasil.
}

Recebido: 28 jan 2019 Aceito: 10 fev 2019

Autor de correspondência: mazzucoc@gmail.com

Conflito de interesses: Os autores declaram não haver nenhum interesse profissional ou pessoal que possa gerar conflito de interesses em relação a este manuscrito.

\section{Resumo}

No Brasil, em 516 dos 5.570 municípios brasileiros o câncer já é a principal causa de morte. A construção das políticas públicas no Sistema Único de Saúde - SUS são por vezes insuficientes e fazem com que a sociedade civil procure o Direito a Saúde através da judicialização. O termo judicialização da saúde refere-se às solicitações demandadas ao poder judiciário, no nível individual ou coletivo, de necessidades em saúde (acesso a serviços e insumos) que não estão sendo atendidas peloSUS, que é assegurado pela Constituição Federal Brasileira promulgada no ano de 1988 e regulamentado por meio da Lei $n^{\circ} 8.080 / 1990$. A $13^{a}$ edição do Relatório Justiça em Números do Conselho Nacional de Justiça, publicado em setembro de 2017, descreve um total de 1.346 .931 processos ajuizados até 2016 relacionados à saúde, destes 312.147 são para fornecimento acesso a medicamentos. Portanto o objetivo deste trabalho é revisar a literatura científica disponível relacionada à judicialização de acesso a medicamentos em oncologia no Brasil entre 2015-2018. Para tal foi realizada uma revisão sistematizada integrativa; considerando que este tipo de revisão de literatura é um método que tem como finalidade sintetizar resultados obtidos em pesquisas sobre um tema ou questão, de maneira sistemática, ordenada e abrangente; fornecendo informações mais amplas sobre um assunto/problema, constituindo, assim, um corpo de conhecimento de um tópico particular. A base de dados utilizada para a busca foi a LILACS. Adotou-se método estruturado, conforme a seguir: (a) formulação do problema/pergunta de investigação; (b) pesquisa na literatura, identificação de fonte a ser consultada, definição de palavras-chave, estratégia de busca, estabelecimento de critérios de inclusão e exclusão; (c) análise dos dados; (d) interpretação dos resultados; e (e) apresentação das conclusões. Os 26 trabalhos identificados e analisados são de revistas brasileiras, contemplando todas as regiões com exceção da Região Norte. A abordagem metodológica mais presente foi a descritiva analítica quali-quantitativa retrospectiva (na qual o objetivo foi descrever e compreender as características da população, do fenômeno, com obtenção de índices numéricos que apontam comportamentos e ações relacionadas aos processos de judicialização anterior a 2018). Algumas aproximações com os artigos incluídos resultaram no entendimento de que a primeira barreira para o acesso a medicamentos, é a insuficiente rede de assistência oncológica. $O$ fenômeno da judicialização por 
acesso a medicamentos ocorre tanto em capitais, como municípios de médio e pequeno porte nas diversas regiões brasileiras. Para o acesso a medicamentos em oncologia, todos os trabalhos mostram que os processos foram impetrados por um único indivíduo, ou seja, ações individuais, e não foram identificadas ações por associações de pacientes. Na oncologia, não há uma lista única de medicamentos selecionados e há protocolos clínicos publicados pelo Ministério da Saúde apenas para alguns tratamentos para os diferentes tipos de tumores. É preciso investimento em diretrizes que estabeleçam qual medicamento ou esquema terapêutico pode ser incluído nos procedimentos de $1 \mathrm{a}, 2$ a ou 3 a linha de tratamento da tabela de Autorização de Procedimentos de Alta Complexidade - APAC, que se baseia nos tipos e estadiamentos tumorais. Uma das razões identificadas nos estudos é a falta dos medicamentos padronizados pelo SUS, nos locais de dispensação. Identificou-se como causa principal a falta de recursos para viabilização do custeio do tratamento. Outro ponto que chama a atenção foi o fato de a maioria das prescrições serem de medicamentos com o nome comercial, não obstante a Lei Federal n. 9.787/1999 obrigar a descrição do medicamento pelo nome genérico na rede do SUS, com pouca divergência de porcentagem entre os estados. A demanda por acesso a medicamentos com indicação off label (indicação não aprovada em bula pela Agência Nacional de Vigilância Sanitária - Anvisa) é pequena. Identificou-se que mais de $90 \%$ dos medicamentos demandados judicialmente eram registrados na Anvisa, e o fenômeno para acesso a medicamentos não registrados na Anvisa é uma exceção. Um dos trabalhos permitiu identificar que a maioria das demandas judiciais em oncologia envolve a assistência farmacêutica (um conjunto de ações voltadas à promoção, proteção e recuperação da saúde, por meio da promoção do acesso aos medicamentos e uso racional desenvolvidas pelo Ministério da Saúde) em especial a farmacoterapia $(78,5 \%)$ e que os instrumentos técnicosanitários atualmente disponíveis para subsidiar as decisões relativas aos medicamentos oncológicos parecem ser insuficientes. No Brasil, com os estudos publicados, pode-se perceber que há indícios da influência da indústria farmacêutica no fenômeno de judicialização a medicamentos inovadores. Conclusões: os trabalhos revisados revelam vários pontos do que se conhece acerca do fenômeno bem como aspectos pouco conhecidos. As reduzidas proporções de medicamentos antineoplásicos e de indicações terapêuticas presentes na lista de medicamentos essenciais da Organização Mundial da Saúde - OMS e nos protocolos clínicos e diretrizes vigentes no país, com vias de financiamento estabelecidas somente para alguns casos específicos, sinalizam a importância de se ampliar o debate na busca de modelos alternativos que garantam a efetiva assistência terapêutica integral aos pacientes em tratamento de câncer no sistema de saúde público brasileiro.

Descritores: Judicialização da Saúde; Sistema Único de Saúde; Oncologia. 